\title{
Época e intensidade de poda no desenvolvimento e produção de amoreira-preta cv. Xavante cultivada em sistema orgânico
}

\author{
Thiago Marchi'* , Doglas Broetto', Alessandro Jefferson Sato', Aline José Maia' \\ Renato Vasconcelos Botelho', Andricia Verlindo² \\ 'Universidade Estadual do Centro-Oeste do Paraná, Unicentro, Guarapuava, PR, Brasil \\ 2Universidade Federal do Paraná, Guarapuava, PR, Brasil \\ *Autor correspondente, e-mail: marchithiago@yahoo.com.br
}

\begin{abstract}
Resumo
A prática da poda de inverno, realizada em frutíferas de clima temperado, tem grande influência no desenvolvimento e produção destas culturas. Variações no sistema de poda podem acarretar em mudanças significativas na época de colheita, produtividade e qualidade de frutos. $O$ presente trabalho teve o objetivo de avaliar os efeitos da época e da intensidade de poda no desenvolvimento e produção da amoreira-preta cv. Xavante em sistema de produção orgânico. O experimento foi conduzido durante as safras de 2009/2010 e 2010/2011 no pomar experimental da Universidade Estadual do Centro-Oeste (Unicentro) em Guarapuava-PR. O delineamento experimental utilizado foi o de blocos casualizados, com cinco repetições em esquema fatorial $2 \times 2$, com duas épocas de poda: precoce e tardia, e duas intensidades de poda dos ramos secundários: curta e longa, totalizando quatro tratamentos. As variáveis analisadas foram: porcentagem de brotação (\%), porcentagem de florescimento (\%), massa média dos frutos (g), número de frutos, sólidos solúveis ( $\left.{ }^{\circ} \mathrm{brix}\right)$, produção por planta $(\mathrm{kg})$, produtividade estimada $\left(\mathrm{kg} \mathrm{ha}^{-1}\right)$ e produção inicial ( $\mathrm{kg}_{\text {planta }}{ }^{-1}$ e \%).A época e a intensidade de poda não influenciaram a massa média dos frutos e os sólidos solúveis. A poda antecipada pode ser uma boa estratégia para se obter maiores produções no início da safra. A poda precoce e longa é a mais recomendada em termos produtivos.
\end{abstract}

Palavras-chave: pequenas frutas, Rubus spp., sazonalidade, tratos culturais

\section{Time and intensity of pruning in the development and production of blackberry cv. Xavante in organic system}

\begin{abstract}
The practice of winter pruning, held in temperate fruit, has great influence on the development and production of these crops. Changes in pruning system may result in significant changes in the time of harvest, yield and fruit quality. This study aimed to evaluate the effects of time and intensity of pruning in the development and production of blackberry cv. Xavante in organic production system. The experiment was conducted during the crop year 2009/2010 and 2010/2011 in the experimental orchard of the State University of Centro-Oeste (Unicentro)Guarapuava - PR. The experimental design was a randomized complete block design with five replications in a $2 \times 2$ factorial design, with two pruning times: early and late, and two intensities of pruning side branches: short and long, a total of four treatments. The variables analyzed were: budding percentage (\%), percentage of flowering $(\%)$, average fruit weight (g), number of fruits, total soluble solids ( $\left.{ }^{\circ} \mathrm{brix}\right)$, yield $(\mathrm{kg})$, estimated yield $\left(\mathrm{kg} \mathrm{ha}^{-1}\right)$ and early yield ( $\mathrm{kg} \mathrm{plant} \mathrm{f}^{-1}$ and \%). The time and intensity of pruning did not influence the average fruit weight and soluble solids. Early pruning can be a good strategy to obtain higher yields in early harvest. Early and long pruning is recommended in the most productive terms.
\end{abstract}

Keywords: crop treatments, Rubus spp., small fruit, seasonality 


\section{Introdução}

A cultura da amoreira-preta encontra-se difundida nos Estados do Sul e Sudeste, ocupando o segundo lugar dentre as pequenas frutas, em produção e área cultivada (Fachinello et al., 2011). Em 2007 havia no Brasil cerca de 250 ha desta frutífera, com produção de 780 toneladas (Strik et al., 2007). Embora não existam dados estatísticos mais recentes, possivelmente estes valores aumentaram. Para Clark \& Finn (2008) os próximos 20 anos são de ótima perspectiva para esta pequena fruta, com grandes incrementos tanto da produção como de consumo.

Esta cultura apresenta algumas peculiaridades que despertam 0 interesse por esta frutífera. Seu cultivo é considerado uma nova opção em várias áreas no mundo, principalmente pela sua rusticidade, adaptandose a uma ampla gama de ambientes e possuindo um custo de produção relativamente baixo. Caracteriza-se também pelo retorno rápido do capital, proporcionando ao pequeno produtor opções de renda, tanto pela destinação do produto ao mercado de frutas frescas quanto para processamento (Antunes, 2002; Attilio et al, 2009; Jacques \& Zambiazi, 2011, Yanamoto et al., 2013).

A amoreira-preta é uma frutífera de clima temperado que exige poda para que possa produzir satisfatoriamente. O objetivo desta operação é regular o vigor das plantas buscando uma produção satisfatória, constante e de boa qualidade. Este manejo é realizado tradicionalmente em dois momentos, no verão, momento em que se eliminam as hastes que produziram e encurtam-se as novas hastes emergidas do solo, e no inverno, reduzindo-se as hastes laterais (Antunes, 2008).

Buscando melhorias e soluções para alguns entraves da cultura, diversos autores já estudaram variações no sistema de poda, tentando encontrar combinações ideais para uma boa produção e qualidade de frutos, além de resolver problemáticas, como a concentração da safra e a baixa durabilidade pós-colheita.

Takeda (2002) testou variações no número de ramos laterais deixados por haste na poda de inverno, com a cultivar 'Black
Satin', em Kearneysville (EUA) e verificou que com o aumento no número de ramos laterais por haste há um decréscimo na brotação de gemas vegetativas e na produção por ramo, já a produção por haste tende a aumentar.

Campagnolo\&Pio (2012b) avaliaram a influencia de seis épocas de poda de inverno na amoreira-preta cv. 'Tupy', na região oeste do Paraná. Os resultados demonstraram que plantas podadas mais tardiamente demandaram menos tempo para iniciar a brotação. Além disso, em anos sem intempéries climáticas a poda realizada na primeira semana de agosto acarreta em maiores valores nas variáveis produtivas, com exceção da massa média dos frutos, que não é alterada.

Neste contexto o objetivo deste trabalho foi avaliar os efeitos da época e da intensidade de poda no desenvolvimento e produção da amoreira-preta cv. Xavante em sistema de produção orgânico na região de GuarapuavaPR.

\section{Material e Métodos}

O experimento foi conduzido durante as safras de 2009/2010 e 2010/2011 no pomar experimental da Universidade Estadual do Centro-Oeste/Unicentro, localizado no município de Guarapuava-PR. O município esta localizado nas coordenadas geográficas: $25^{\circ}$ $23^{\prime} 26^{\prime \prime} \mathrm{S}$ e $51^{\circ} 27^{\prime} 15^{\prime \prime} \mathrm{O}$, altitude média de 1.120 m, com clima subtropical mesotérmico-úmido (Cfb), sem estação seca, com verões frescos e inverno moderado segundo classificação de Köppen (IAPAR, 2012). Os dados climáticos, com temperatura média e pluviosidade semanal, durante o período de agosto a fevereiro dos anos agrícolas em estudo, foram fornecidos pela estação meteorológica da própria universidade (Figura 1).

Para a realização do experimento foram utilizadasamoreiras-preta da cv. Xavante. Esta cultivar é o resultado do trabalho em conjunto da Embrapa Clima Temperado de Pelotas e da Universidade de Arkansas (EUA) e apresentou boa adaptabilidade as condições de Guarapuava-PR (Botelho et al., 2009; Clark \& Finn, 2011). Possui porte ereto, hastes vigorosas e sem espinhos, com baixa necessidade de 
frio e boa produtividade. As frutas têm forma alongada, firmeza média, sabor doce-ácido, predominando a acidez (Antunes, 2008).

A área experimental foi implantada em 2004, sendo as plantas distribuídas no espaçamento $1,0 \times 4,0 \mathrm{~m}$ e conduzidas em sistema de dupla espaldeira. O manejo do pomar durante o experimento foi realizado segundo as normas de produção orgânica, sem a aplicação de insumos sintéticos, realizando roçadas nas entre linhas para o manejo de plantas invasoras, adubação orgânica e somente a aplicação de produtos fitossanitários recomendados.
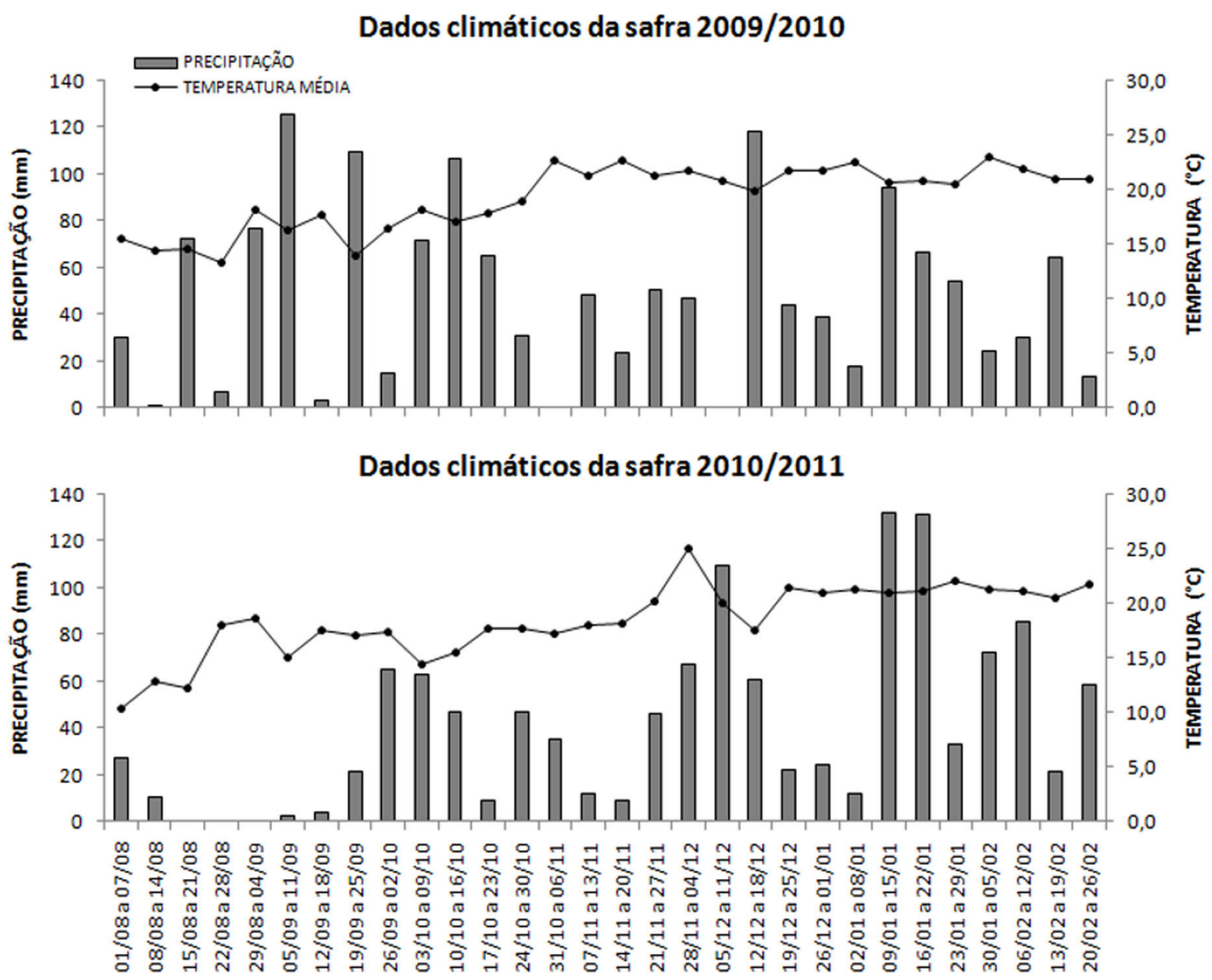

Figura 1. Dados climáticos de temperatura média e pluviosidade semanal de agosto a fevereiro de 2009/2010 e 2010/2011 no município de Guarapuava - PR.

O delineamento experimental utilizado foi 0 de blocos casualizados, com cinco repetições em esquema fatorial $2 \times 2$, com duas épocas de poda: precoce (realizada em 7 de agosto de 2009 e de 2010) e tardia (realizada em 29 de agosto de 2009 e 11 de setembro de 2010); e duas intensidades de poda dos ramos secundários: curta e longa, que se caracterizaram pelo corte após a $4^{a}$ e $8^{a}$ gema lateral, respectivamente. A parcela experimental foi constituída por uma planta conduzida com 4 hastes.

As avaliações realizadasforam: porcentagemde brotação (\%), sendo considerada a porcentagem de gemas brotadas (em estádio de brotação ponta verde), avaliadas semanalmente; porcentagem de florescimento (\%), sendo considerada a porcentagem de flores abertas, avaliadas semanalmente; massa média dos frutos (g); número de frutos por planta; sólidos solúveis ( ${ }^{\circ}$ brix), avaliados com refratômetro digital, somente na safra 2009/2010; produção por planta (kg); produtividade estimada ( $\mathrm{kg} \mathrm{ha}$ 1. Além destas, devido ao fato de não serem observadas diferenças nas épocas de início da colheita entre os diferentes tratamentos, decidiu-se comparar o volume de produção das primeiras três semanas de safra e a sua 
participação na produção total, variável que foi denominadaprodução inicial ( $\mathrm{kg}$ planta $^{-1}$ e \%). A colheita dos frutos foi realizada de duas a três vezes por semana por ocasião da maturação dos mesmos, por parâmetro visual de avaliação (coloração roxa escura).

Com os dados das taxas de brotação e de florescimento foram plotadas curvas e osdemais dados obtidos foram submetidos à análise de variância; quando significativa, as médias foram comparadas pelo Teste de Tukey ao nível de $5 \%$ de probabilidade, utilizando-se o programa estatístico SISVAR 5.0 (Ferreira, 2011).

\section{Resultados e Discussão}

A porcentagem de brotação (Figura 2) foi influenciada pela época de poda. Nas duas safras estudadas a poda tardia causou atrasos no início e no desenvolvimento da abertura de gemas vegetativas. Para atingir $50 \%$ de brotação, plantas podadas tardiamente levaram três a quatro semanas a mais que plantas podadas precocemente.

$\mathrm{Na}$ safra 2009/2010, as plantas submetidas às podas precoces curta e longa apresentaram porcentagens de brotação semelhantes nas oito primeiras semanas após a poda. Para plantas podadas tardiamente esta semelhança foi de apenas duas semanas, sendo que após esse período as plantas foram influenciadas pela intensidade de poda. A partir da terceira semana após a realização da poda, as plantas que receberam a poda longa e tardia tiveram as menores porcentagens de brotação em todas as avaliações.

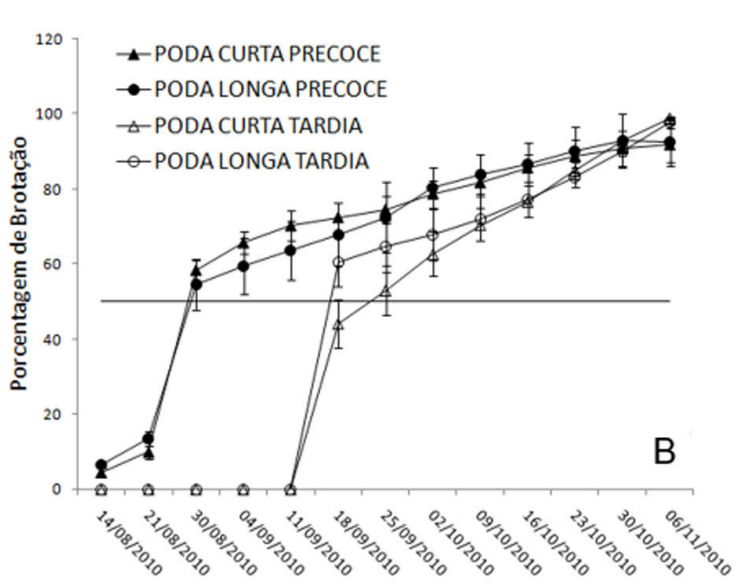

Figura 2. Evolução da porcentagem de brotação de amoreira-preta cv. Xavante, submetidas a diferentes podas de inverno, nas safras 2009/2010 (A) e 2010/2011 (B). Guarapuava-PR.

Na safra 2010/2011, uma semana após a realização da poda tardia, não foi encontrada diferença entre as plantas que receberam a poda tardia e longa e as plantas que receberam podas precoces. Quatro semanas após a realização da poda tardia não foram mais encontradas diferenças entre os tratamentos para porcentagem de brotação.

Referente às porcentagens de florescimento (Figura 3), na safra 2009/2010 a época e a intensidade de poda não influenciaram significativamente esta variável. Porém no ano agrícola de 2010/201 1, houve uma diferença durante as cinco primeiras semanas do experimento, em que plantas podadas tardiamente apresentaram menor porcentagem de flores abertas neste período, reiterando
- ocorrido com as gemas vegetativas.Desta forma, entende-se que a poda realizada mais tardiamente acarreta um desenvolvimento inicial mais lento da planta, apesar de não modificar o início do evento de floração.Campagnolo\& Pio (2012b) observaram que plantas podadas entre a segunda quinzena de junho e a segunda quinzena de agosto(um intervalo de praticamente 60 dias), apresentaram uma diferença de apenas 12 dias no primeiro ciclo e 7 dias no segundo ciclo estudados para iniciar o florescimento.Com a abertura de menos flores no início do ciclo da cultura, pode-se sugerir que a época de poda poderia ser utilizada como estratégia de escape em regiões que ocorrem geadas tardias. 

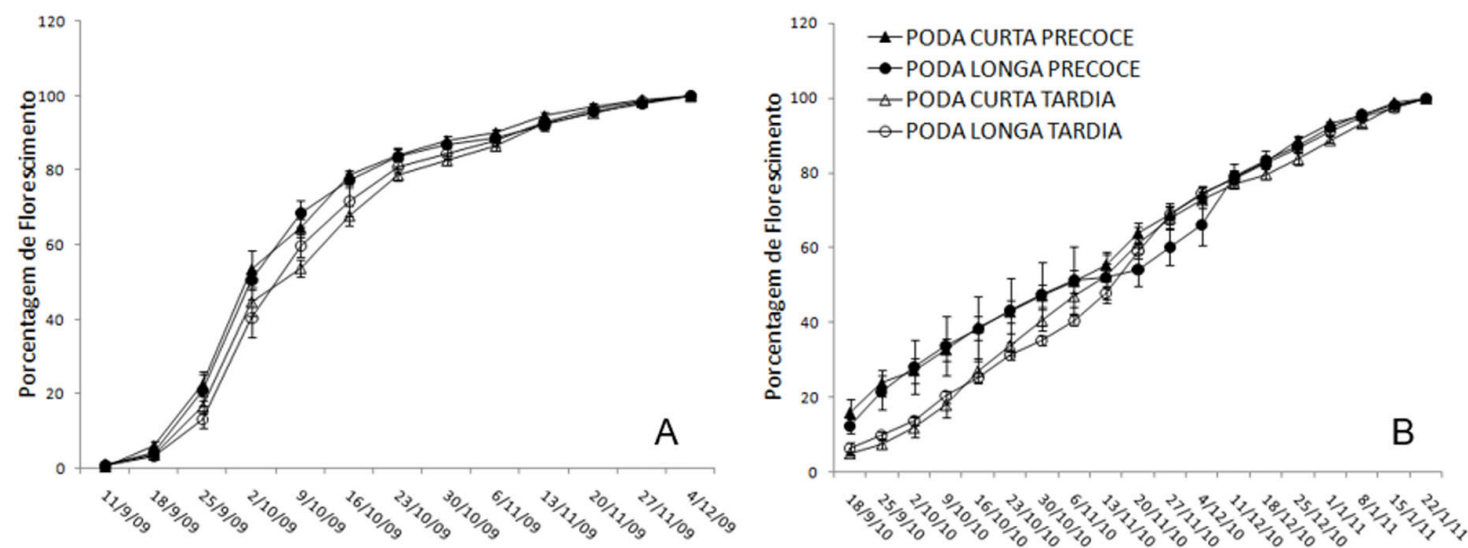

Figura 3. Evolução da porcentagem de florescimento de amoreira-preta cv. Xavante, submetidas a diferentes podas de inverno, nas safras 2009/2010 (A) e 2010/2011 (B). Guarapuava-PR.

Na tabela 1 estão presentes os quadrados médios e os resultados do teste $\mathrm{F}$ das variáveis analisadas.

As variáveis massa média dos frutos e sólidos solúveis não sofreram influência significativa da época e da intensidade de poda, sendo que em geral os frutos apresentaram média de 4,03 g e 7,14 'brix, respectivamente (Tabela 1). Estes valores são inferiores aos citados por Antunes (2008), que caracteriza a amoreirapreta $\mathrm{cv}$. Xavante com massa média próxima a $6 \mathrm{~g}$ e teores de sólidos solúveis de 8 brix, e aos encontrados por Botelho et al. (2009), para esta mesma cultivar no município de Guarapuava-PR, que verificaram massa média de $4,9 \mathrm{~g}$ e sólidos solúveis de 9,2 ${ }^{\circ}$ brix em duas safras estudadas. Estes mesmos autores sugerem que apesar de a amoreira-preta ser autofértil, esta diferença de massa pode ser atribuída a problemas com a polinização, advinda de interferências ambientais ou presença de insetos-praga atacando a flor.Diferentes manejos de poda não têm demonstrado alteraçãonestas variáveis (Takeda, 2002; Campagnolo \& Pio, 2012a; Tullio \& Ayub, 2013).

Tabela 1. Quadrados médios e resultados do teste F das variáveis analisadas. Guarapuava-PR.

\begin{tabular}{|c|c|c|c|c|c|c|c|c|}
\hline \multicolumn{9}{|c|}{ Quadrados Médios Safra 2009/2010 } \\
\hline $\begin{array}{l}\text { Causas Da } \\
\text { Variação }\end{array}$ & $\mathrm{Gl}$ & $\begin{array}{l}\text { Massa } \\
\text { Média } \\
\text { De Frutos }\end{array}$ & $\begin{array}{l}\text { Número De } \\
\text { Frutos Por } \\
\text { Planta }\end{array}$ & $\begin{array}{l}\text { Produção } \\
\text { Por Planta }\end{array}$ & $\begin{array}{c}\text { Produtividade } \\
\text { Estimada }\end{array}$ & $\begin{array}{l}\text { Produção } \\
\text { Inicial (Kg } \\
\text { Planta-1) }^{-1}\end{array}$ & $\begin{array}{l}\text { Produção } \\
\text { Inicial (\%) }\end{array}$ & $\begin{array}{l}\text { Sólidos } \\
\text { Solúveis }\end{array}$ \\
\hline Época & 1 & $0,04050^{\mathrm{Ns}}$ & $180500,0^{*}$ & $3,82113^{*}$ & $23894073,0125^{*}$ & $6,66204^{* *}$ & $1341,522^{* *}$ & $0,04050^{\mathrm{Ns}}$ \\
\hline Intensidade & 1 & $0,00128^{\mathrm{Ns}}$ & $339561,8^{* *}$ & $5,79534^{* *}$ & $36216824,1125^{* *}$ & $1,31431^{*}$ & $34,322^{\mathrm{Ns}}$ & $0,3645^{\mathrm{Ns}}$ \\
\hline Interação & 1 & $0,10952^{\mathrm{Ns}}$ & $12103,2^{\mathrm{Ns}}$ & $0,68450^{\mathrm{Ns}}$ & $4276275,2^{\mathrm{Ns}}$ & $0,18374^{\mathrm{Ns}}$ & $19,602^{\mathrm{Ns}}$ & $0,0245^{\mathrm{Ns}}$ \\
\hline Resíduo & 12 & 0,05565 & 38313,825 & 0,51417 & 3214936,137 & 0,27329 & 32,94158 & 0,509 \\
\hline Média & & 4,151 & 1026,3 & 4,2578 & 10644,15 & 2,41285 & 55,85 & 7,145 \\
\hline CV (\%) & & 5,68 & 19,07 & 16,84 & 16,85 & 21,67 & 10,28 & 9,99 \\
\hline \multicolumn{9}{|c|}{ Quadrados Médios Safra 2010/2011 } \\
\hline $\begin{array}{l}\text { Causas Da } \\
\text { Variação }\end{array}$ & $\mathrm{Gl}$ & $\begin{array}{l}\text { Massa } \\
\text { Média } \\
\text { De Frutos }\end{array}$ & $\begin{array}{l}\text { Número De } \\
\text { Frutos Por } \\
\text { Planta }\end{array}$ & $\begin{array}{l}\text { Produção } \\
\text { Por Planta }\end{array}$ & $\begin{array}{c}\text { Produtividade } \\
\text { Estimada }\end{array}$ & $\begin{array}{l}\text { Produção } \\
\text { Inicial (Kg } \\
\left.\text { Planta }^{-1}\right)\end{array}$ & $\begin{array}{l}\text { Produção } \\
\text { Inicial (\%) }\end{array}$ & \\
\hline Época & 1 & $0,28084^{\mathrm{Ns}}$ & $78487,9205^{* *}$ & $2,17206^{* *}$ & $13575845,2086^{* *}$ & $6,22059 * *$ & $6749,138^{* *}$ & \\
\hline Intensidade & 1 & $0,12641^{\mathrm{Ns}}$ & $529,4205^{\mathrm{Ns}}$ & $0,02093^{\mathrm{Ns}}$ & $131014,34065^{\mathrm{Ns}}$ & $0,0252^{\mathrm{Ns}}$ & $7,20^{\mathrm{Ns}}$ & \\
\hline Interação & 1 & $0,0042^{\mathrm{Ns}}$ & $9035,5005^{\mathrm{Ns}}$ & $0,18682^{\mathrm{Ns}}$ & $1170442,82964^{\mathrm{Ns}}$ & $0,33179^{\mathrm{Ns}}$ & $204,80^{\text {Ns }}$ & \\
\hline Resíduo & 12 & 0,06512 & 8155,968 & 0,21364 & 1080814,117 & 0,06396 & 44,18392 & \\
\hline Média & & 3,915 & 626,045 & 2,46445 & 6161,2615 & 0,9066 & 34,47 & \\
\hline CV (\%) & & 6,52 & 14,43 & 18,76 & 16,87 & 27,9 & 19,28 & \\
\hline
\end{tabular}


Os resultados de número de frutos por planta não apresentaram constância nas safras estudadas (Tabela 2). Na safra 2009/2010, somente a intensidade de poda resultou em diferença estatística, sendo que a poda longa resultou em maior número de frutos. Sabe-se que a produção da amoreira-preta é dependente, em parte, do número de gemas deixado nas hastes após a poda de inverno (Takeda, 2002). A redução do número de hastes e a diminuição do comprimento das hastes laterais geralmente diminuem a produção devido ao menor número de gemas florais, mas pode melhorar a qualidade do fruto em amoras e framboesas (Crandall\&Daubeny, 1990). Na safra seguinte o número de frutos sofreu uma redução drástica, possivelmente devido à estiagem que ocorreu nos meses de agosto e início de setembro. Neste ciclo somente a época de poda resultou em diferença para esta variável, sendo que a poda precoce realizada em meados de agosto acarretou em maior número de frutos por planta.

Nas duas safras estudadas as plantas podadas precocemente atingiram maior produção inicial por planta e maiores valores de participação da produção inicial na produção total (Tabela 2). A poda precoce elevou em 1,16 e $1,11 \mathrm{~kg}$ planta $^{-1} \mathrm{a}$ produção das três primeiras semanas, na primeira e segunda safra estudada, respectivamente, o que representa 16,38 e $36,74 \%$ a mais no período, em relação à poda tardia. Dalastra et al. (2009), trabalhando com diferentes épocas de poda da figueira 'Roxo de Valinhos' na região oeste do Paraná, verificaram maiores produtividades no início da safra de plantas podadas nos primeiros dias de julho e agosto, enquanto as plantas podadas no início de setembro apresentaram resultados inferiores para este período. Este fato sugere que a poda antecipada pode ser uma forma de se conseguir maiores produções no início da safra, podendo esta ser uma estratégia para se alcançar melhores preços no mercado de frutas frescas, ou ainda de escalonar a produção das plantas e aproveitar melhor a mão-de-obra.

Tabela 2. Efeito da época e intensidade de poda da amoreira-preta cv. Xavante nas variáveis número de frutos por planta e produção inicial (kg planta-1) e (\%). Guarapuava-PR.

\begin{tabular}{|c|c|c|c|c|c|c|c|}
\hline \multirow{3}{*}{ Variável } & \multirow{3}{*}{$\begin{array}{l}\text { Intensidade de } \\
\text { poda }\end{array}$} & \multicolumn{3}{|c|}{$2009 / 2010$} & \multicolumn{3}{|c|}{$2010 / 2011$} \\
\hline & & \multicolumn{2}{|c|}{ Época de Poda } & \multirow{2}{*}{ Média } & \multicolumn{2}{|c|}{ Época de Poda } & \multirow{2}{*}{ Média } \\
\hline & & Precoce & Tardia & & Precoce & Tardia & \\
\hline \multirow{3}{*}{$\begin{array}{c}\text { Número de frutos } \\
\text { por planta }\end{array}$} & Poda Curta & 966,4 & 825,6 & $896,0 \mathrm{~b}$ & 704,8 & 537,0 & $620,90 a$ \\
\hline & Poda Longa & 1276,2 & 1037,0 & 1156,6 a & 672,58 & 589,80 & $631,19 a$ \\
\hline & Média & $1121,3 \mathrm{~A}$ & $931,3 \mathrm{~A}$ & 1026,3 & $688,69 \mathrm{~A}$ & $563,40 \mathrm{~B}$ & 626,04 \\
\hline \multirow{3}{*}{$\begin{array}{c}\text { Produção } \\
\text { inicial(kg planta-1) }\end{array}$} & Poda Curta & 2,64 & 1,67 & $2,16 \mathrm{~b}$ & 1,63 & 0,25 & $0,94 a$ \\
\hline & Poda Longa & 3,34 & 1,99 & $2,67 \mathrm{a}$ & 1,30 & 0,44 & $0,87 a$ \\
\hline & Média & $2,99 \mathrm{~A}$ & $1,83 \mathrm{~B}$ & 2,41 & $1,46 \mathrm{~A}$ & $0,35 \mathrm{~B}$ & 0,907 \\
\hline \multirow{3}{*}{$\begin{array}{l}\text { Produção } \\
\text { inicial(\%) }\end{array}$} & Poda Curta & 66,34 & 47,98 & $57,16 a$ & 55,44 & 12,30 & $33,87 a$ \\
\hline & Poda Longa & 61,74 & 47,34 & $54,54 a$ & 50,24 & 19,90 & $35,07 \mathrm{a}$ \\
\hline & Média & $64,04 \mathrm{~A}$ & $47,66 \mathrm{~B}$ & 55,85 & $52,84 \mathrm{~A}$ & $16,10 \mathrm{~B}$ & 34,47 \\
\hline
\end{tabular}

A produção total por planta e a produtividade estimada foram influenciadas pela época e intensidade de podas (Figura 4). Quanto ao fator época, a poda precoce resultou em maiores valores, alcançando médias de 4,69 e 2,79 kg planta-1 e 11,74 e 6,98 t ha-1 nas safras de 2009/2010 e 2010/2011, respectivamente. Em relação ao fator intensidade, na safra 2009/2010 as plantas que receberam a poda longa obtiveram maiores valores de produção por planta (4,8 kg planta $\left.{ }^{-1}\right)$ e produtividade estimada $\left(11,99+\mathrm{ha}^{-1}\right)$, porém os mesmos resultados não foram observados na safra seguinte, onde não houve diferença significativa entre as diferentes intensidades de poda.Possivelmente, além das condições adversas de clima que ocorreram neste ciclo, a elevada produtividade do ciclo anterior pode ter influenciado. Neste caso, a alta produtividade acarretou em depleção das reservas, comprometendo a produção da safra seguinte, causa esta mais iminente nas plantas que receberam a poda longa. 

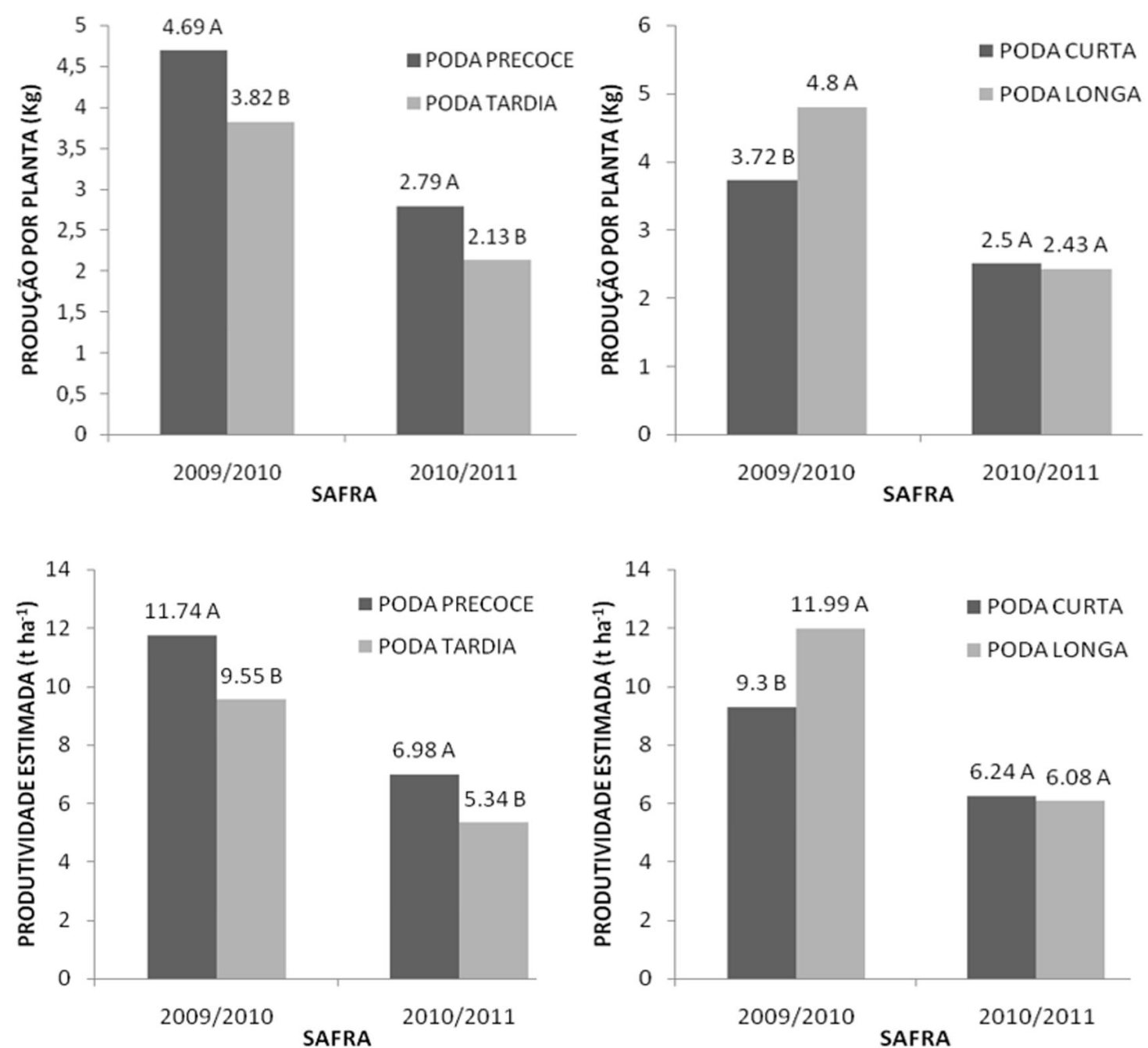

Figura 4. Produção por planta $(\mathrm{Kg})$ e Produtividade estimada $\left(t^{\left.\mathrm{ha}^{-1}\right)}\right.$ de amoreiras submetidas a diferentes épocas e intensidades de poda, nas safras 2009/2010 e 2010/2011. Guarapuava-PR. Médias seguidas de mesma letra não diferem estatisticamente entre si pelo teste de Tukey a $5 \%$ de probabilidade.

\section{Conclusões}

1. A época de poda altera o início e a época de brotação das gemas vegetativas de amoreiras-preta cv. Xavante;

2. A época e a intensidade de poda não influenciam os parâmetros de qualidade (massa média de frutos e sólidos solúveis) de amoraspretas;

3. A poda antecipada pode ser uma boa estratégia para se obter maiores produções no início da safra;

4. A poda precoce e longa é a mais recomendada em termos produtivos.

\section{Referências}

Antunes, L.E.C. 2002. Amora-preta: nova opção de cultivo no Brasil. Ciência Rural 32:151-158.

Antunes, L.E.C. (ed.) Sistema de produção da amoreira-preta.2008.http://sistemasdeproducao.
cnptia.embrapa.br/FontesHTML/Amora/ SistemaProducaoAmoreiraPreta/index.htm <Acesso em: 19 jan. 2014>

Attilio, L.B., Boliani, A.C., Tarsitano, M.A.A. 2009. Custo de produção de amora-preta em região tropical. Revista Brasileira de Fruticultura 31:10421047.

Botelho, R.V., Pavanello, A.P., Broetto, D., Scisloski, S.F., Baldissera, T.C. 2009. Fenologia e produção da amoreira-preta sem espinhos cv. Xavante na região de Guarapuava-PR. Scientia Agraria 10:209-214.

Campagnolo, M.A., Pio, R. 2012a. Poda drástica para a produção de amora-preta. Pesquisa Agropecuária Brasileira 47:934-938.

Campagnolo, M.A., Pio, R. 2012b. Produção da amoreira-preta 'Tupy' sob diferentes épocas de poda. Ciência Rural 42:225-231.

Clark, J.R., Finn, C.E. 2008. New trends in blackberry breeding. Acta Horticulturae 777:41-47. 
Clark, J.R., Finn, C.E. 2011. Blackberry breeding and genetics. Fruit, Vegetable and Cereal Science and Biotechnology 5:27-43.

Crandall, P.C., Daubeny, H.A. 1990. Raspberry management. In: Galletto, G.J.,Himelrick, D.G. (ed.) Small fruit crop management. Prentice Hall, New Jersey, USA. p. 157-213.

Dalastra, I.M., Pio, R., Campagnolo, MA., Dalastra, G.M., Chagas, E.A., Guimarães, V.F. 2009. Épocas de poda na produção de figos verdes 'roxo de valinhos' em sistema orgânico na região oeste do Paraná. Revista Brasileira de Fruticultura 31: 447-453.

Fachinello, J.C., Pasa, M.S., Shmtiz, J.D., Betemps, D.L. 2011 . Situação e perspectivas da fruticultura de clima temperado no Brasil. Revista Brasileira de Fruticultura 33:109-120.

Ferreira, D.F. 2011. Sisvar: a computerstatisticalanalysis system. Ciência e Agrotecnologia 35:1039-1042.

IAPAR - Instituto Agronômico do Paraná. 2012. Carta Climática do Paraná. http:// www.iapar.br/modules/conteudo/conteudo. php? conteudo=597 <Acesso em 10 Nov. 2013>

Jacques, A.C., Zambiazi, R.C. 2011 . Fitoquímicos em amora-preta (Rubusspp). Semina: Ciências Agrárias 32: 245-260.

Strik, B.C., Clark, J.R., Finn, C.E., Bañados, M.P. 2007. Worldwide blackberry production. HortTechnology 17: 205-213.

Takeda, F. 2002. Winter pruning affects yield components of "Black Satin" Eastern Thornless blackberry. HortScience 37: 101-103.

Tullio, L., Ayub, R.A. 2013. Produção da amorapreta cvtupy, em função da intensidade da poda. Semina: Ciências Agrárias 34:1147-1 152.

Yanamoto, L.Y., Koyama, R., Borges, W.F.S., Antunes, L.E.C., Assis, A.M., Roberto, S.F. 2013. Substratos no enraizamento de estacas herbáceas de amora-preta Xavante. Ciência Rural 43: 15-20. 